\title{
Evaluation of Preschool Children with the Diagnosis of Non-epileptic Paroxysmal Disorders in a Pediatric Neurology Outpatient Clinic
}

\author{
D Tuğçe Aksu Uzunhan
}

Istanbul Okmeydanı Training and Research Hospital, Clinic of Children's Health and Diseases, İstanbul, Turkey

\section{Abstract}

Objective: Recurrent non-epileptic disorders that differ according to age play an important role in the differential diagnosis of childhood epilepsy. The aim of this study was to evaluate preschool children with recurrent non-epileptic paroxysmal disorders who were admitted to a pediatric neurology outpatient clinic.

Methods: Seventy-five children younger than 6 years of age who were admitted to a pediatric neurology outpatient clinic between January 2017 and January 2018 due to recurrent non-epileptic disorders were included in the study. The number of patients presenting with seizures and all other diagnoses were also recorded. Descriptive statistical analyses and chi-square test were used as statistical methods.

Results: Of the patients, 36 were female (48\%) and 39 (52\%) were male. The mean age was $22.5 \pm 17.2$ months, with the youngest patient being 2 months and the oldest patient being 69 months old. Sixteen different diagnoses were detected. The prevalance of the disorder among 1575 new patients was $4.7 \%$. The two most common diagnoses were breath-holding spells and gratification disorder. Of all patients, 29 patients (39\%) had breath-holding spells and 46 (61\%) had other diagnoses. Episode during examination happened most commonly in tic disorders, and least commonly in breath-holding spells and gratification disorder. The need for home video recording for diagnosis was mostly in patients with gratification disorder. Episode during examination, and need for video recording, sleep electroencephalography and cranial magnetic resonance imaging were significantly lower in breath-holding spells compared with other diagnoses $(p<0.05)$. Children with the diagnoses of breathholding spells was prescribed and used more iron formulations and piracetam than the patients with other non-epileptic paroxysmal disorders ( $p<0.05)$.

Conclusion: Home video recordings can prevent a misdiagnosis of epilepsy in patients with recurrent non-epileptic paroxysmal disorders. Accurate and timely diagnosis is possible without the need for further examination with medical history only in cases where the clinical symptoms are stereotypic.

Keywords: Differential diagnosis, epilepsy, preschool children

\section{INTRODUCTION}

Paroxysmal non-epileptic disorders of childhood are complex conditions involving recurrent intermittent motor movements, behavioral changes and somatic symptoms. These recurrent, sudden starting and ending movements that last seconds or minutes can occur at any age (1). The examples include sleep myoclonus for newborn age, breath-holding spells and gratification disorder for infants, and and tic and night terrors for preschool children. Epileptic seizures are quite common in the pediatric population, and the annual prevalence of epilepsy is around $0.5-1 \%$ (2). When paroxysmal disorders are encountered in childhood, epileptic seizures come to mind first. Therefore, patients with paroxysmal non-epileptic disorders are sometimes diagnosed with epilepsy and subjected to unnecessary investigations and treatment. In a retrospective study conducted in the UK, it was found that 44 (35\%) out of 125 children who were referred with the diagnosis of epilepsy had no epilepsy (3). Accurate diagnosis may be delayed due to the presence of different disorders for each age group, limited facility for video electroencephalography (EEG) monitoring, and inadequate access to tertiary pediatric neurology centers. In a study from the United States, 134 children with paroxysmal non-epileptic disorders were evaluated and the time from onset of symptoms to diagnosis was found to be 1.35 years (3 weeks-4 years) (4). Increased knowledge and experience of paroxysmal non-epileptic disorders for each age group will prevent the misdiagnosis of epilepsy and therefore will reduce the use of antiepileptic drugs 
with high potential of side effects and ensure that patients are followed up with accurate diagnosis. The aim of this study was to evaluate the clinical and laboratory characteristics of infants and preschool children admitted to the pediatric neurology outpatient clinic with paroxysmal disorders, and diagnosed with paroxysmal non-epileptic disorder, and to investigate the prevalance of the disorder in the pediatric neurology outpatient clinic compared with seizures and epilepsies.

\section{METHODS}

Seventy-five children under 6 years of age who were admitted to the pediatric neurology outpatient clinic of Okmeydanı Training and Research Hospital between January 2017 and January 2018 due to paroxysmal non-epileptic disorders were included in the study. Patients with the diagnosis of syncope were not included in the study in terms of cardiologic etiologies in the differential diagnosis of syncope. The collected data were as follows: gender, age, duration of follow-up, complaints, duration of complaints, frequency of complaints, definitive diagnosis, episode during examination, need for video for diagnosis, request for sleep EEG, request for cranial magnetic resonance imaging (MRI), EEG results, cranial MRI results, antiepileptic use, whether there was a definitive diagnosis of epilepsy, neurological examination, laboratory test results, results of radiological and electrophysiological examinations, results of pediatric cardiology consultation and other departments included in the consultation, and iron and piracetam drug use. The families of the patients were asked to videotape the complaints in order to evaluate the disorders. The parents of the patients with missing data were contacted by phone and the missing data were completed, and data regarding the latest status of the patient, newly added diagnoses, episode status, and the changes in episodes were updated. However, five out of 75 patients could not be reached by phone. The frequency of the investigated disorder was also examined in our outpatient clinic by evaluating the number of patients under 6 years of age who were admitted to the pediatric neurology outpatient clinic for febrile seizures and epilepsy, and the number of new patients from the same age group admitted during this period.

\section{Statistical Analysis}

The analysis was performed using the Statistical Package for the Social Sciences 23 (SPSS, Armonk, NY: IBM Corp.). For numerical variables, mean, standard deviation, minimum and maximum values were given. For categorical variables, frequency distributions (number, percentage) were given. Independent Samples t-test was used to determine the difference between the

\begin{tabular}{|c|c|c|c|}
\hline Gender & n (\%) & & \\
\hline Female & $36(48 \%)$ & & \\
\hline Male & $39(52 \%)$ & & \\
\hline \multicolumn{4}{|l|}{ Age group } \\
\hline Infant & $48(64 \%)$ & & \\
\hline Preschool child & 27 (52\%) & & \\
\hline \multicolumn{4}{|l|}{ Complaint frequency } \\
\hline Daily & $42(56 \%)$ & & \\
\hline Frequently & $15(20 \%)$ & & \\
\hline Occasionally & $12(16 \%)$ & & \\
\hline Rarely & $6(8 \%)$ & & \\
\hline \multicolumn{4}{|l|}{ Neurological examination } \\
\hline Normal & $71(95 \%)$ & & \\
\hline Abnormal & $4(5 \%)$ & & \\
\hline Complaint & $\mathrm{n}$ & Final diagnosis & n (\%) \\
\hline Cyanosis while crying & 29 & $\begin{array}{l}\text { Breath-holding } \\
\text { spell }\end{array}$ & $\begin{array}{l}29 \\
(38.7 \%)\end{array}$ \\
\hline $\begin{array}{l}\text { Scissoring of lower } \\
\text { extremities }\end{array}$ & 12 & $\begin{array}{l}\text { Gratification } \\
\text { disorder }\end{array}$ & $12(16 \%)$ \\
\hline $\begin{array}{l}\text { Waking up with fear } \\
\text { from sleep at night }\end{array}$ & 5 & Night terror & $5(6.7 \%)$ \\
\hline $\begin{array}{l}\text { Suppressible involuntary } \\
\text { movements }\end{array}$ & 4 & Tic disorder & $4(5.3 \%)$ \\
\hline Jerking & 4 & $\begin{array}{l}\text { Benign } \\
\text { myoclonus of } \\
\text { infancy }\end{array}$ & $4(5.3 \%)$ \\
\hline Jerking & 1 & Hyperexplexia & $1(1.3 \%)$ \\
\hline $\begin{array}{l}\text { Throwing head back and } \\
\text { sideways }\end{array}$ & 4 & $\begin{array}{l}\text { Sandifer } \\
\text { syndrome }\end{array}$ & $4(5.3 \%)$ \\
\hline Head nodding & 1 & Head nodding & $1(1.3 \%)$ \\
\hline Head nodding & 2 & \multirow{2}{*}{$\begin{array}{l}\text { Idiopathic } \\
\text { infantile } \\
\text { nystagmus }\end{array}$} & \multirow[b]{2}{*}{$3(4 \%)$} \\
\hline $\begin{array}{l}\text { Nystagmus and bending } \\
\text { the neck }\end{array}$ & 1 & & \\
\hline Staring & 3 & Staring attack & $3(4 \%)$ \\
\hline $\begin{array}{l}\text { Nystagmus and bending } \\
\text { the neck }\end{array}$ & 1 & Spasmus nutans & $1(1.3 \%)$ \\
\hline Shuddering & 2 & $\begin{array}{l}\text { Shuddering } \\
\text { attack }\end{array}$ & $2(2.7 \%)$ \\
\hline Nystagmus and dizziness & 2 & $\begin{array}{l}\text { Benign } \\
\text { paroxysmal } \\
\text { vertigo }\end{array}$ & $2(2.7 \%)$ \\
\hline Hand turning & 1 & \multirow{2}{*}{$\begin{array}{l}\text { Nonspecific } \\
\text { paroxysmal non- } \\
\text { epileptic disorder }\end{array}$} & \multirow[b]{2}{*}{$2(2.7 \%)$} \\
\hline $\begin{array}{l}\text { Hand flapping when } \\
\text { excited }\end{array}$ & 1 & & \\
\hline Jerking in the legs & 1 & Jitteriness & $1(1.3 \%)$ \\
\hline Cyanosis & 1 & $\begin{array}{l}\text { Gastroesophageal } \\
\text { reflux }\end{array}$ & $1(1.3 \%)$ \\
\hline
\end{tabular}


two groups. Chi-square test was used to examine the relationship between categorical variables and test results are given in tables.

\section{RESULTS}

Between January 2017 and January 2018, a total of 1575 new patients under the age of 6 were admitted to the pediatric neurology outpatient clinic and 485 (31\%) of them were evaluated for febrile seizures and epilepsy. Paroxysmal nonepileptic disorder was considered in 75 patients (4.7\%). Of the patients, 36 were female (48\%) and 39 were male (52\%). The mean age was $22.5 \pm 17.2$ months and median age was 17 months. The youngest patient was 2 months old and the oldest one was 69 months old. Forty-eight patients (64\%) were infants and 27 (36\%) were preschool children. The duration of complaints was $7.44 \pm 9.23$ months with a median of 5 months. The most common complaints were cyanosis while crying and scissoring of the lower limbs, and the first two diagnoses were breath-holding spells and gratification disorders. All of our breath-holding spells were cyanotic. The youngest patient was diagnosed with jitter and the oldest patient was diagnosed with tic disorder. Sixteen different diagnoses were determined and the least common diagnosis was gastroesophageal reflux. Table 1 presents demographic data, complaints, frequency of complaints, definitive diagnosis and neurological examinations of all patients. The definitive diagnoses of patients with handturning and hand flapping complaints when getting excited were classified as non-specific paroxysmal non-epileptic disorder. As breath-holding spells were the most common diagnosis, seventeen patients (35\%) were infants and 12 patients (44\%) were preschool children. Episodes during the examination were observed most frequently in patients with tic disorder and least frequently in patients with breath-holding spells and pediatric gratification disorders. The need for video for diagnosis was most commonly seen in patients with childhood gratification disorder, followed by infantile benign myoclonus and Sandifer syndrome (Table 2). Of all patients, 29 (39\%) were diagnosed with breath-holding spells while remaining 46 (61\%) were diagnosed with other etiologies. Episode rate, video request rate, sleep EEG request rate and cranial MRI request rate were found to be lower in patients diagnosed with breath-holding spells than those with other diagnoses $(p<0.05)$ (Table 3). None of the patients diagnosed with breath-holding spells were requested for video for the diagnosis, three patients were requested for EEG and one patient for cranial MRI, and two patients admitted with EEG results requested from an external center and all were normal. Pediatric cardiology consultation was performed in 25 (86\%) of 29 patients with breath-holding spells, and it was found that 15 patients (60\%) had normal results, six patients (24\%) had patent

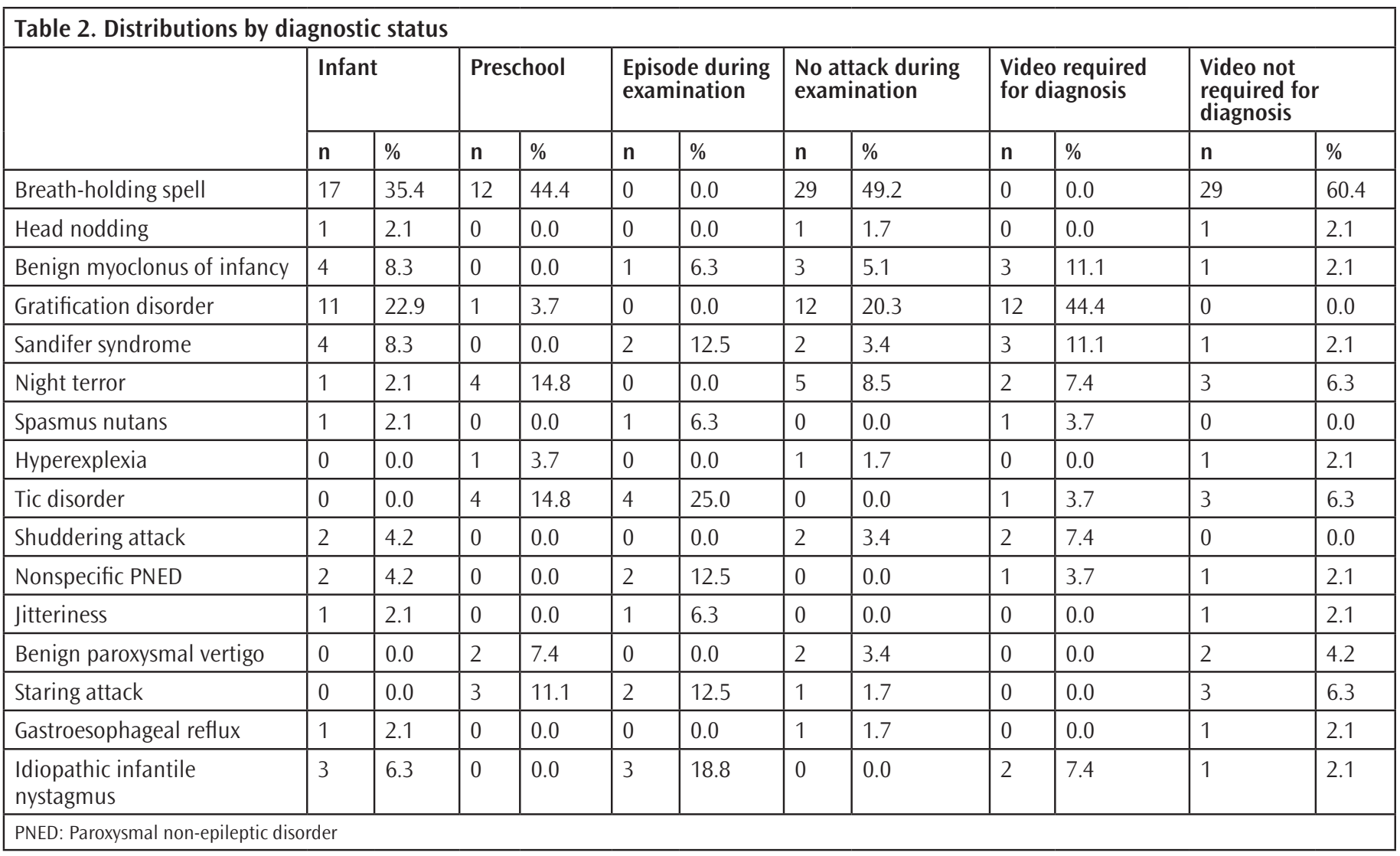


foramen ovale and four patients (16\%) had other diagnoses [atrial septal defect (ASD)/ventricular septal defect, ASD, mitral regurgitation, bicuspid aortic regurgitation/ascending aortic dilatation], respectively. On the other hand, pediatric cardiology consultation was performed in 14 patients without breathholding spells, and secundum ASD, operated transposition of the great artery and aortic dilatation were detected in three patients. None of the patients diagnosed with breath-holding spells underwent consultation except for pediatric cardiology. Among patients with non-breath-holding spells, two patients underwent pediatric gastroenterology consultation, one underwent ear nose throat consultation, and one underwent ophthalmology consultation. The rate of cranial MRI request in patients who had an episode during the examination was statistically higher than those who had no episode during the examination $(p<0.05)$, but the difference in terms of request for sleep EEG and video EEG for diagnosis was not statistically significant (Table 4). The definitive diagnosis of epilepsy was present in three patients. One of them was hospitalized in neonatal intensive care unit in the newborn period because of Meconium Aspiration syndrome, and diagnosed as West syndrome. The same patient later developed Sandifer's syndrome after feeding with nasogastric tube, and her complaints regressed after percutaneous endoscopic gastrostomy was performed. The other patient had cryptogenic West syndrome and had a childhood gratification disorder. The last patient underwent surgery at the age of 1 week due to transposition of great arteries and had global development delay and childhood gratification disorder.

The use of iron and piracetam as treatment was significantly higher in patients with breath-holding spells than those with other diagnoses $(p<0.05)$ (Table 3). Twenty (69\%) of 29 patients

\begin{tabular}{|c|c|c|c|c|c|c|c|}
\hline \multirow[b]{2}{*}{$\mathrm{n}$} & & \multicolumn{2}{|c|}{ Breath-holding spell } & \multicolumn{2}{|c|}{ Others } & \multirow[t]{2}{*}{ Chi-square } & \multirow[t]{2}{*}{$p$} \\
\hline & & $\%$ & $n$ & $\%$ & & & \\
\hline \multirow[t]{2}{*}{ Gender } & Female & 12 & 41.4 & 24 & 52.2 & \multirow[t]{2}{*}{0.830} & \multirow[t]{2}{*}{0.362} \\
\hline & Male & 17 & 58.6 & 22 & 47.8 & & \\
\hline \multirow[t]{2}{*}{ Age group } & Infant & 17 & 58.6 & 31 & 67.4 & \multirow[t]{2}{*}{0.594} & \multirow[t]{2}{*}{0.441} \\
\hline & Preschool & 12 & 41.4 & 15 & 32.6 & & \\
\hline \multirow[t]{2}{*}{ Episode during examination } & Yes & 0 & 0.0 & 16 & 34.8 & \multirow[t]{2}{*}{12.822} & \multirow[t]{2}{*}{$0.000 * * *$} \\
\hline & No & 29 & 100.0 & 30 & 65.2 & & \\
\hline \multirow[t]{2}{*}{ Video for diagnosis } & Yes & 0 & 0.0 & 27 & 58.7 & \multirow[t]{2}{*}{26.596} & \multirow[t]{2}{*}{$0.000 * *$} \\
\hline & No & 29 & 100.0 & 19 & 41.3 & & \\
\hline \multirow[t]{2}{*}{ Sleep EEG request } & Yes & 3 & 10.3 & 17 & 37.0 & \multirow[t]{2}{*}{6.441} & \multirow[t]{2}{*}{$0.011^{*}$} \\
\hline & No & 26 & 89.7 & 29 & 63.0 & & \\
\hline \multirow[t]{2}{*}{ Cranial MRI request } & Yes & 1 & 3.4 & 10 & 21.7 & \multirow[t]{2}{*}{4.755} & \multirow[t]{2}{*}{$0.042 *$} \\
\hline & No & 28 & 96.6 & 36 & 78.3 & & \\
\hline \multirow[t]{3}{*}{ EEG result } & Normal & 5 & 17.2 & 16 & 34.8 & \multirow[t]{3}{*}{-} & \multirow[t]{3}{*}{-} \\
\hline & Epilepsy & 0 & 0.0 & 3 & 6.5 & & \\
\hline & None & 24 & 82.8 & 27 & 58.7 & & \\
\hline \multirow[t]{3}{*}{ MRI result } & Normal & 0 & 0.0 & 8 & 17.4 & \multirow[t]{3}{*}{-} & \multirow[t]{3}{*}{-} \\
\hline & Abnormal & 0 & 0.0 & 2 & 4.3 & & \\
\hline & None & 29 & 100.0 & 36 & 78.3 & & \\
\hline \multirow[t]{2}{*}{ Iron } & Yes & 20 & 69.0 & 0 & 0.0 & \multirow[t]{2}{*}{43.260} & \multirow[t]{2}{*}{$0.000 * * *$} \\
\hline & No & 9 & 31.0 & 46 & 100.0 & & \\
\hline Piracetam & Yes & 5 & 17.2 & 0 & 0.0 & 8.498 & $0.007^{* *}$ \\
\hline & No & 24 & 82.8 & 46 & 100.0 & & \\
\hline Final status of the episodes & Yes & 9 & 31.0 & 23 & 50.0 & - & - \\
\hline & No & 19 & 65.5 & 19 & 41.3 & & \\
\hline & Unknown & 1 & 3.4 & 4 & 8.7 & & \\
\hline
\end{tabular}


with breath-holding spells were treated with iron. Only five patients (17\%) were given piracetam treatment. Regarding response to treatment, there was no significant difference between those treated with iron and piracetam and those who were not treated. The mean follow-up was $19.17 \pm 4.74$ months and the median was 20 months. At the end of the follow-up period, episodes disappeared in 39 patients (52\%), while 20 (51\%) of them had breath-holding spells. The remaining \%48 of the patients still had episodes, while the oldest patient with breath-holding spells was 45 months of age, but the frequency of the episodes decreased. Number of episodes had decreased in 21 patients (28\%), of which eight patients (38\%) had breathholding spells. There was no change in the frequency of the episodes in nine patients (12\%), of which four had gratification disorders, two had idiopathic infantile nystagmus, one had benign myoclonus of early infancy, night terror and shuddering attack. Complaints were increased in one patient (1\%) diagnosed with gratification disorder and five patients (7\%) could not be reached, so the final status could not be evaluated. At the end of the follow-up period, no new patients with the diagnosis of epilepsy were detected at the final evaluation.

\section{DISCUSSION}

There are different diseases according to age in the differential diagnosis of childhood paroxysmal non-epileptic disorders. The most common diagnoses are jitteriness in newborns, breathholding spells in infants and preschool children, and syncope, migraine and its variants and pseudoseizure in adolescents (5).
In our study, breath-holding spells were found to be the most common diagnosis in infants and preschool children, followed by gratification disorder. Jitteriness was not diagnosed in the newborn period in the present study, except in a 2-month-old infant. In cyanotic breath-holding spells, the child screams, cyanoses, jerks, loses and regains consciousness within seconds in the presence of anger and frustration (6). The rates of requesting video, sleep EEG and cranial MRI were significantly lower in our patients with breath-holding spells than in other patients. As in our study, this clinical picture is so stereotypic that recognition of symptoms overcomes diagnostic investigations. In the preschool period, patients with symptoms that may suggest epileptic seizures such as jerking and fainting should be questioned if they cry before the episode. The pallid breathholding spells resemble syncope, develop after pain and fear, crying is minimal and silent, patients become pale and lose consciousness, and bradycardia occurs (7). All patients in our study were evaluated as cyanotic breath-holding spells. The paleness of the spell with unnoticed triggers may confuse the physicians with the diagnosis of syncope. In our study, pediatric cardiology evaluation was performed in 25 (86\%) of 29 patients with breath-holding spells. In a study of 115 patients with long QT syndrome, breath-holding spells were identified as presenting symptom in one (4.3\%) of 23 symptomatic patients. In a study conducted in our country, the prevalence of breath-holding spells was found to be $3.6 \%$ (8) and it was expressed that the frequency of long QT syndrome was not significantly different from the prevalence in the community. However, evaluation of long QT syndrome was recommended in patients with a history

\begin{tabular}{|c|c|c|c|c|c|c|c|}
\hline \multirow{2}{*}{\multicolumn{2}{|c|}{$\mathrm{n}$}} & \multicolumn{2}{|c|}{$\begin{array}{l}\text { Attack during } \\
\text { examination }\end{array}$} & \multicolumn{2}{|c|}{$\begin{array}{l}\text { No attack during } \\
\text { examination }\end{array}$} & \multirow[t]{2}{*}{ Chi-square } & \multirow[t]{2}{*}{ p } \\
\hline & & $\%$ & $n$ & $\%$ & & & \\
\hline \multirow[t]{2}{*}{ Sleep EEG request } & Yes & 7 & 43.8 & 13 & 22.0 & \multirow[t]{2}{*}{3.035} & \multirow[t]{2}{*}{0.112} \\
\hline & No & 9 & 56.3 & 46 & 78.0 & & \\
\hline \multirow[t]{2}{*}{ Cranial MRI request } & Yes & 6 & 37.5 & 5 & 8.5 & \multirow[t]{2}{*}{8.473} & \multirow[t]{2}{*}{$0.009^{*}$} \\
\hline & No & 10 & 62.5 & 54 & 91.5 & & \\
\hline \multirow[t]{3}{*}{ EEG result } & Normal & 7 & 43.7 & 14 & 23.7 & \multirow[t]{3}{*}{-} & \multirow[t]{3}{*}{ - } \\
\hline & Epilepsy & 1 & 6.3 & 2 & 3.4 & & \\
\hline & None & 8 & 50.0 & 43 & 72.9 & & \\
\hline \multirow[t]{3}{*}{ MRI result } & Normal & 6 & 37.5 & 2 & 3.4 & \multirow[t]{3}{*}{-} & \multirow[t]{3}{*}{ - } \\
\hline & Abnormal & 1 & 6.3 & 1 & 1.7 & & \\
\hline & None & 9 & 56.3 & 56 & 94.9 & & \\
\hline \multirow{2}{*}{$\begin{array}{l}\text { Video demand for } \\
\text { diagnosis }\end{array}$} & Yes & 7 & 43.8 & 20 & 33.9 & \multirow[t]{2}{*}{0.530} & \multirow[t]{2}{*}{0.467} \\
\hline & No & 9 & 56.3 & 39 & 66.1 & & \\
\hline
\end{tabular}


of loss of consciousness, persistent episodes over 6 years of age, fainting attacks, arrhythmia and sudden death in the family (9). Iron deficiency anemia has been implicated in the etiology of breath-holding spells, and low hemoglobin $(\mathrm{Hb})$ and inadequate brain oxygenation are risk factors for breath-holding spells (10). According to Cochrane analysis, iron treatment given at a dose of $5 \mathrm{mg} / \mathrm{kg} /$ day for 16 weeks has been reported to be effective in reducing the frequency and severity of spells. It has been reported that supplement treatment is much more beneficial especially in children with iron deficiency anemia, and it is correlated with $\mathrm{Hb}$ levels, but it may also be useful in children who are not anemic and who do not have lower levels of $\mathrm{Hb}$ (11). Piracetam, the cyclic derivative of gamma-aminobutyric acid (GABA), is also used in the treatment of breath-holding spells. It has been suggested that it can prevent breath-holding spells by showing inhibitory effect like GABA does in the brain. In a double blind, placebo-controlled study, there was a significant reduction in spells in the patient group receiving piracetam for 4 months (12). In our study, the rate of iron and piracetam use was significantly higher in patients with breath-holding spells than those with other diagnoses. Twenty patients (69\%) with breathholding spells were treated with iron, while the remaining nine patients (31\%) were not treated. Only five patients (17\%) were given piracetam treatment. It is known that the spells disappear after the age of 5, regardless of whether treatment is given (7). In our study, there was no patient over 5 years old with a history of breath-holding spells. Home video recordings are the most important tools in the evaluation of childhood paroxysmal nonepileptic disorders after detailed history and observation. Since video EEG examination is not always available, video recordings of episodes may prevent complex examinations and/or the use of unnecessary antiepileptic drugs for the treatment of the disorder in the presence of normal neuromotor development and physical examination findings and normal interictal EEG findings. In our study, video recordings of episodes were requested from all patients diagnosed with gratification disorder and the diagnosis was made by examining the video recordings. Another group of diseases where home video records are valuable is benign myoclonus of infancy. Alvarez suggested the definition of benign polymorphous movement disorder in infancy for the diagnosis of shuddering attacks and benign infantile myoclonus (13). In our study, benign infantile myoclonus was seen in $4(5.3 \%)$ of 75 patients. Due to its paroxysmal character, it is believed that more than half of the patients are mistakenly thought to have West syndrome or one of the epileptic syndromes such as myoclonic infantile epilepsy in the world. However, the diagnosis of epilepsy should be met with suspicion, especially in patients who are less than 18 months old, with typical normal development, normal EEG and episodes with features that separate them from epileptic seizures (13). In our study, epilepsy was not detected in any of these patients during the 2-year follow-up period. The prevalence of paroxysmal non-epileptic disorders was $4.7 \%$ in our pediatric neurology outpatient clinic. The prevalence of febrile convulsions and epilepsy constitutes 31\% of our pediatric neurology outpatient clinic. In the pediatric epilepsy-monitoring unit where 883 patients were evaluated with long-term video EEG monitorization over a six-year period, 134 patients (15.2\%) had paroxysmal nonepileptic disorder. Stereotypic movements, sleep myoclonus, parasomnias and Sandifer syndrome were the most common diagnoses in 26 preschool children. Coincidental epilepsy was reported in 12 patients (46\%) in preschool period (14). In our study, epilepsy and coincidental paroxysmal non-epileptic disorders were detected in three patients (4\%) simultaneously. The reason for this difference is that the patients referred to the epilepsy monitoring unit due to long term video EEG monitorization request were more likely to have epilepsy and that our study was performed on paroxysmal non-epileptic disorders detected in patients who were admitted to the our outpatient clinic with paroxysmal episodes. However, it should be kept in mind that patients with epilepsy may have simultaneous paroxysmal non-epileptic disorders. For the first time in 1933, Wyllie and Schlesinger described recurrent fever, headache, vomiting and abdominal pain episodes in children as "childhood periodic disorder". Nowadays, childhood periodic syndromes are defined as childhood benign paroxysmal torticollis, childhood benign paroxysmal vertigo, abdominal migraine and cyclic vomiting syndrome (15). In our study, we had two children with benign paroxysmal vertigo. Benign paroxysmal vertigo is characterized by nausea, dizziness and nystagmus attacks that start between 2-4 years of age. It may progress to migraine in the future. Plays such as swings, seesaws that stimulate the labyrinth in the inner ear, fatigue, stressful situations, fever, and awakening from sleep can also trigger attacks (15). Accurate diagnosis will not only prevent unnecessary antiepileptic use, but will also help to eliminate triggering factors. In this study, patients admitted to a pediatric neurology outpatient clinic due to paroxysmal non-epileptic disorders with 16 different diagnoses were evaluated retrospectively. Although the data used in the literature are frequently obtained from video EEG monitoring centers, the data in our study belonged to a pediatric neurology outpatient clinic where patients were referred by a family physician or pediatrician, therefore, the diagnoses were so variable not to be encountered in a video EEG 
monitoring center. Albeit our patients did not have video EEG monitoring, no epileptic diagnosis was found in any patient during a follow-up of two years.

\section{CONCLUSION}

Paroxysmal non-epileptic disorders are a common diagnostic group in childhood. Patients who cannot be diagnosed accurately and timely are mistakenly diagnosed with epilepsy and they use unnecessary antiepileptic drugs. Since there is no laboratory test to confirm the diagnosis, careful evaluation of clinical findings and home video recordings will provide clues to the diagnosis in many patients.

\section{Ethics}

Ethics Committee Approval: Ethics committee approval was received from istanbul Okmeydanı Training and Research Hospital Ethics Committee (approval number: 09.01.2018/808).

Informed consent: Informed consent was obtained from the parents of all patients who participated in the study.

Peer-review: Externally peer-reviewed.

Financial Disclosure: The author declared that this study has received no financial support.

\section{REFERENCES}

1. Tatli B, Guler S. Non epileptic paroxysmal events in childhood. Türk Pediatr Ars 2017;52:59-65.
2. Mikati MA, Hani AJ. Seizures in childhood. Kliegman RM, F SB, editors. Nelson Textbook of Pediatrics. Philadelphia: Elsevier; 2011.p.2791-959.

3. Uldall P, Alving J, Hansen LK, Kibaek M, Buchholt J. The misdiagnosis of epilepsy in children admitted to a tertiary epilepsy centre with paroxysmal events. Arch Dis Child 2006;91:219-21.

4. Kotagal P, Costa M, Wyllie E, Wolgamuth B. Paroxysmal nonepileptic events in children and adolescents. Pediatrics 2002;110:e46.

5. Paolicchi JM. The spectrum of nonepileptic events in children. Epilepsia 2002;43Suppl3:60-4.

6. Breningstall GN. Breath-holding spells. Pediatr Neurol 1996;14:91-7.

7. Leung AKC, Leung AAM, Wong AHC, Hon KL. Breath-Holding Spells in Pediatrics: A Narrative Review of the Current Evidence. Curr Pediatr Rev 2018;14:22-9.

8. Carman KB, Ekici A, Yimenicioglu S, Arslantas D, Yakut A. Breath holding spells: Point prevalence and associated factors among Turkish children. Pediatr Int 2013;55:328-31.

9. Robinson JA, Bos JM, Etheridge SP, Ackerman MJ. Breath Holding Spells in Children with Long QT Syndrome. Congenit Heart Dis 2015;4:354-61.

10. Hamed SA, Gad EF, Sherif TK. Iron deficiency and cyanotic breath-holding spells: The effectiveness of iron therapy. Pediatr Hematol Oncol 2018;35:18695.

11. Zehetner AA, Orr N, Buckmaster A, Williams K, Wheeler DM. Iron supplementation for breath-holding attacks in children. Cochrane database Syst Rev 2010;5:CD008132.

12. Sawires $\mathrm{H}$, Botrous 0 . Double-blind, placebo-controlled trial on the effect of piracetam on breath-holding spells. Eur J Pediatr 2012;171:1063-7.

13. Fernández-Alvarez E. Transient benign paroxysmal movement disorders in infancy. Eur J Paediatr Neurol 2018;22:230-7.

14. Kotagal P, Costa M, Wyllie E, Wolgamuth B. Paroxysmal Nonepileptic Events in Children and Adolescents. Pediatrics 2004;110:e46-e46.

15. Cuvellier J-C, Lépine A. Childhood Periodic Syndromes. Pediatr Neurol 2010;42:1-11. 